\title{
The features of bone articular lesions in dialysis-related amyloidosis (DRA) and criteria for the clinical diagnosis of DRA
}

\author{
Shinichi Nishi ${ }^{*}$, Suguru Yamamoto ${ }^{2}$, Junichi Hoshino ${ }^{3}$, Kenmei Takaichi $^{3}$ and Hironobu Naiki ${ }^{4}$
}

\begin{abstract}
We introduced criteria for the clinical diagnosis of dialysis-related amyloidosis (DRA) from the Amyloidosis Research Group study supported by a Grant-in-Aid from the Ministry of Health, Labour and Welfare of Japan. DRA exhibits various kinds of bone articular lesions, such as carpal tunnel syndrome, trigger finger, destructive spondyloarthropathy, spinal canal stenosis, and joint pains. These bone articular lesions, excluding destructive spondyloarthropathy, are observed in non-dialysis patients or dialysis patients without DRA. We carefully compared these lesions between DRA and non-DRA patients and summarized the differences between them. The incidence age, male to female ratio, and coincidence rate were distinct between these groups of patients. Biopsies from bone articular lesions are invasive and burdensome for dialysis patients; therefore, a precise clinical diagnosis is required for DRA. We discussed the validity and availability of our proposed criteria.
\end{abstract}

Keywords: Amyloidosis, Carpal tunnel syndrome, Trigger finger, Destructive spondyloarthropathy, Joint pains

\section{Background}

Dialysis-related amyloidosis (DRA) is a type of systemic amyloidosis. Compared to the clinical features of other types of systemic amyloidosis, such as immunoglobulin light chain amyloidosis (AL) and inflammatory amyloidosis (AA) types, the clinical features of DRA are distinct in terms of preferential amyloid deposition at multiple bone articular lesions. Initially, carpal tunnel syndrome (CTS) was reported as a common bone articular lesion of DRA [1, 2]. Consequently, trigger finger (TF) [3], destructive spondyloarthropathy (DSA) [4, 5], spinal canal stenosis (SCS) [6], and joint pains [7, 8] have been identified as bone articular lesions associated with DRA.

Fundamentally, the diagnosis of amyloidosis should be determined via precise pathological examinations, including Congo red staining, green color polarization, and immunohistostaining with specific antibodies to the precursor proteins. Tissue specimens obtained from the gastrointestinal mucosa, kidney, liver, and heart are

\footnotetext{
* Correspondence: snishi@med.kobe-u.ac.jp

${ }^{1}$ Division of Nephrology and Kidney Center, Graduate School of Medicine, Kobe University, 7-5-2 Kusunoki-cho, Chuou-ku Kobe City, Hyogo Prefecture 650-0017, Japan

Full list of author information is available at the end of the article
}

typically available for histological examination in AA and AL amyloidosis. Although the biopsy specimens from bone articular lesions are indeed necessary for the exact examination of DRA, compared with organ tissue biopsies, biopsies from bone articular lesions are invasive and technically difficult due to enclosed and narrow environments. Additionally, a biopsy from bone articular lesions becomes burdensome for DRA patients. Surgical tissues from bone articular lesions have been used limitedly for histological diagnosis in DRA.

In this review, we summarized the issues concerning the diagnosis of DRA and introduced criteria for the clinical diagnosis of DRA.

\section{Criteria for the clinical diagnosis of DRA}

In Japan, we have already proposed criteria for the clinical diagnosis of dialysis-related amyloidosis (DRA) in 2010 from the Amyloidosis Research Group study supported by a Grant-in-Aid from the Ministry of Health, Labour and Welfare of Japan [9].

We surveyed the prevalence of bone articular lesions from dialysis patients with various vintage groups, ranging from short to long. We asked three dialysis institutes to randomly select each 5 patients from 4 vintage

(c) The Author(s). 2019 Open Access This article is distributed under the terms of the Creative Commons Attribution 4.0 International License (http://creativecommons.org/licenses/by/4.0/), which permits unrestricted use, distribution, and 
groups, 0 to 5 years, 5 to 10 years, 10 to 15 years, and greater than 15 years. All 60 cases were subject to medial interviews for signs and symptoms concerning bone articular lesions associated with DRA, and patients were subject to X-rays of the spine and joints, including wrist, shoulder, hip, and knee. The diagnosis of bone articular lesions associated with DRA was clinically performed by doctors based on patients' complaints and bone X-rays.

Figure 1 presents the prevalent rates of DRA lesions. Among them, multiple joints pain $(48.3 \%)$ was the most common. The rates of other lesions, such as CTS and $\mathrm{TF}$, were less than $25 \%$.

Table 1 presents the proposed criteria. Five major findings are proposed: two bone articular lesions, and three minor findings. DSA and SCS were integrated into one category, namely, dialysis spinal lesions, because they were occasionally observed in the same lesions. We defined cases with two or more major findings as definitive cases and cases with one major finding plus one or more minor findings as doubtful cases.

The following diseases were established as exclusion criteria: rheumatoid arthritis, osteoarthritis joint, pyogenic arthritis, gout, pseudogout cervical or lumbar spondylosis, and suppurative spondylitis.

Figure 2 revealed definitive and doubtful cases in 4 vintage groups: 0 to 5 years, 5 to 10 years, 10 to 15 years, and greater than 15 years. According to the vintage groups, definitive cases increased, representing $26.7 \%$ of 60 total cases. In contrast, $13.3 \%$ of the total cases were doubtful. Interestingly, it has been reported that the levels of pre-dialysis serum beta- 2 microglobulin which was a precursor protein of DRA were not significantly associated with the odds ratio for CTS or the prevalence of DRA $[10,11]$.

\section{How to diagnose bone articular lesions observed in dialysis patients}

In daily medical practices, orthopedic examinations are fundamental for the diagnosis of bone articular lesions. First, we summarized the orthopedic criteria and methods in the diagnosis of bone articular lesions associated with DRA based on previously published articles. Second, we compared the clinical differences of bone articular lesions between patients with and without DRA (Table 2).

\section{CTS}

A medical interview is a basic procedure for the diagnosis of carpal tunnel syndrome (CTS). American Academy of Neurology (AAN) clinical diagnostic criteria [12] noted that the following symptoms represent typical findings: paraesthesia, pain, swelling, weakness or clumsiness of the hand provoked or worsened by sleep, sustained hand or arm position, repetitive action of the hand or wrist that is mitigated by changing posture or by shaking the hand; sensory deficit or hypotrophy of the median innervated thenar muscle.

El Miedany et al. [13] reported that provocative tests, such as Tinel's, Phalen's, reverse Phalen's, and carpal tunnel compression tests, were not highly sensitive or specific tests for the diagnosis of CTS. The highest sensitivity was $47 \%$ in Phalen's test and the highest specificity was $65 \%$ in Tinel's test in patients diagnosed by AAN criteria. Although the nerve conduction test assists

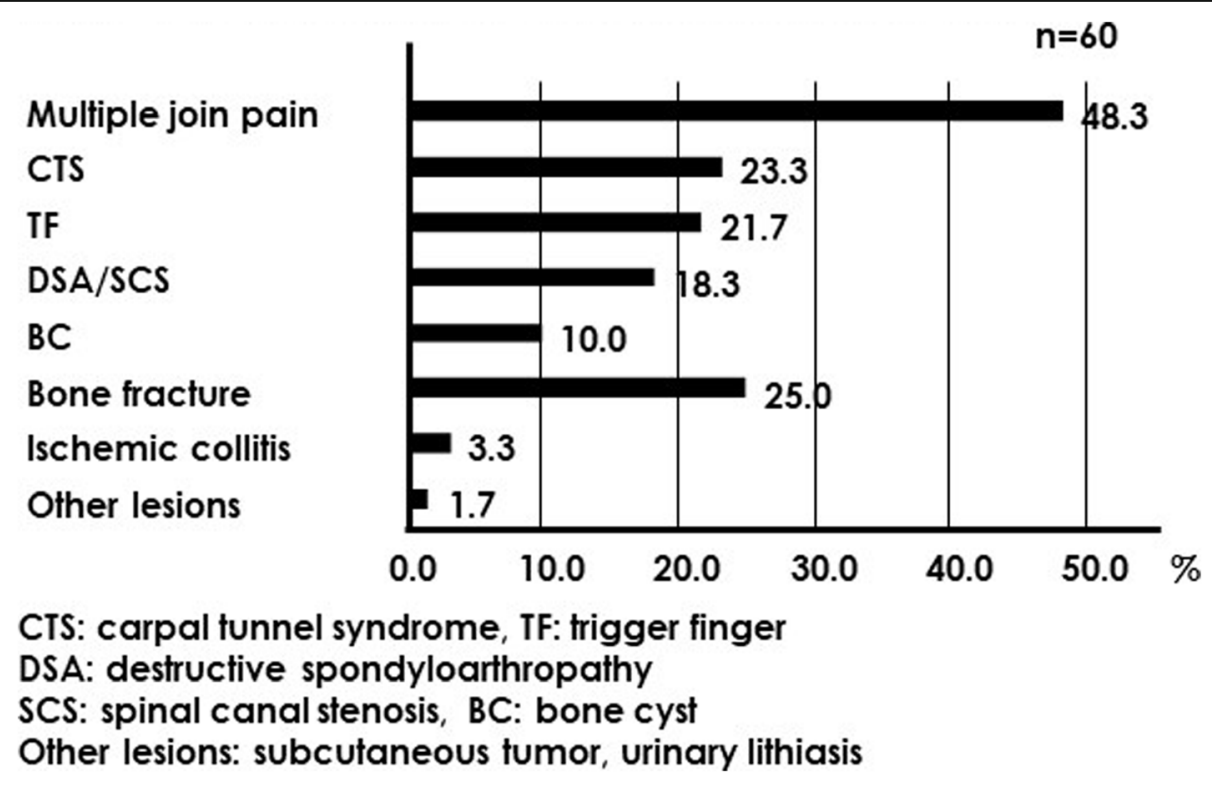

Fig. 1 The prevalence of each DRA-associated lesion in various dialysis vintage groups $(n=60)$ 
Table 1 Criteria for the clinical diagnosis of dialysis-related amyloidosis

Major findings
1. Multiple joints pain
2. Carpal tunnel syndrome
3. Trigger finger
4. Dialysis spinal lesions (destructive spondyloarthropathy or spinal
canal stenosis)
5. Bone cyst
Minor findings
1. Bone fracture
2. Ischemic colitis
3. Other lesions: subcutaneous skin tumor, urolithiasis
Definitive case: patient with two or more major findings
Doubtful case: patient with one major finding plus one or more
accessory findings
Exclusion criteria
Osteoarthritis, rheumatoid arthritis, infectious arthritis, gout,
pseudogout
Lumbar or cervical spondylosis, pyogenic spondylitis

in the diagnosis of CTS, $31.5 \%$ of positive Phalen's cases and $23.6 \%$ of positive Tinel's tests exhibited normal findings in nerve conduction tests.

Ultrasonographic diagnosis is helpful for the diagnosis of CTS; however, this technique cannot perfectly diagnose CTS. Kolovos et al. [14] measured the anteroposterior to transverse diameter of the median nerve inside the canal and at its entrance by sonography. They concluded that a gray zone existed in between patients with CTS and healthy persons. Based on these comments, sensitive and objective diagnosis methods are lacking; thus, clinical diagnosis is the best method for the diagnosis of CTS.

Compared with CTS in non-dialysis patients, the clinical features of CTS associated with DRA are distinctive based on the following points. The female ratio is dominant in non-dialysis CTS. In contrast, the male to female ratio is approximately even in CTS-associated DRA. Guan et al. [15] reported that the female ratio was 91.8\% in 1360 cases with non-dialysis CTS. In contrast, Hoshino et al. [16] reported that female ratios were $43.6 \%$ and $50.4 \%$ in a large Japanese dialysis cohort who received carpal tunnel release operation for CTS in 1998 $(n=647)$ and $2010(n=2157)$, respectively. Another distinct point is the bilateral progression in dialysis CTS as well as AL or AA amyloidosis [17]. Unilateral development is common in non-dialysis CTS.

In terms of the gender difference and bilateral lesions, CTS associated with DRA exhibits distinctive clinical features compared with CTS without DRA (Table 1).

\section{TF}

Although the diagnostic criteria of trigger finger (TF) have not been reported in previous articles and textbooks, only the criteria of clinical classification have been reported. The severity of the trigger finger was graded by Newport et al. [18]. They defined three clinical grades of symptoms as follows. Grade I was considered a simple tenosynovitis with tenderness and pain but

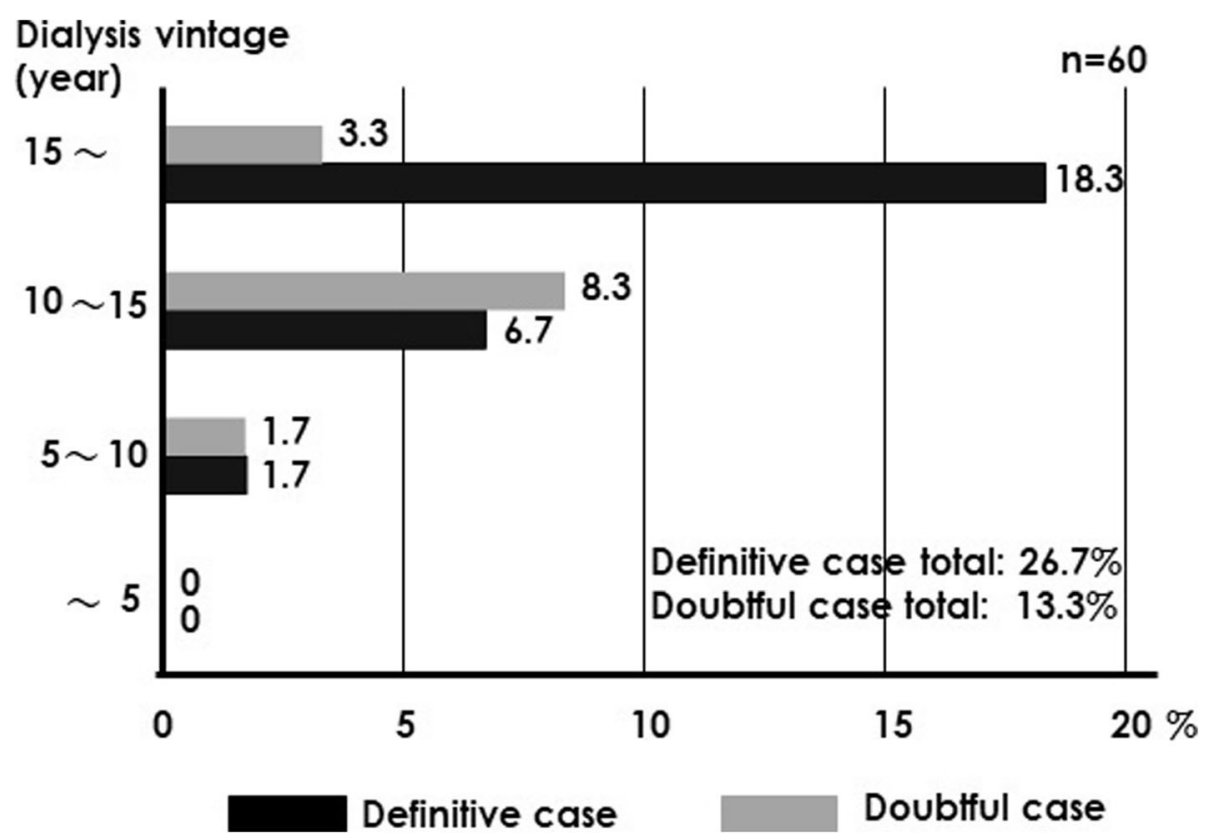

Fig. 2 The diagnosis rates of DRA, definitive and doubtful cases in each dialysis vintage group 
Table 2 Comparison of bone articular lesions between non-dialysis and dialysis patients

\begin{tabular}{lll}
\hline & Non-dialysis patients & Dialysis patients \\
\hline CTS & Female dominant & Female and male ratio, even \\
& Unilateral lesion, common & Bilateral lesions, common \\
TF & CTS and TF coincidence, less & CTS and TF coincidence, more \\
DSA & None & Specifically found \\
SCS & No relationship between CTS and TF & Appearance after CTS and TF \\
BC & Incident age, young & Incident age, old \\
\hline
\end{tabular}

$C T S$, carpal tunnel syndrome; TF, trigger finger; DSA, destructive spondyloarthropathy; SCS, spinal canal stenosis; $B C$, bone cyst

without a palpable nodule or triggering. Grade II is characterized by fingers with demonstrated tenderness, a swelling or nodularity of the tendon, and occasional catching or triggering. Grade III is the category with the most severe symptoms, including all manifestations of grade II as well as frequent catching, triggering, or locking. McKee et al. [19] reported that greater than half of non-dialysis patients (52\%) exhibited spontaneous resolution without any surgical intervention. Spontaneous resolution is rare in TF in dialysis patients. The coincidence rates might not be negligible between CTS and TF in dialysis patients (Table 1). Lin et al. [20] reported that TF developed in $8.5 \%$ non-dialysis patients after a carpal tunnel release operation. In our analysis of long-term dialysis patients with DRA, 27.0\% cases $(n=$ 20 in total of 74 cases) exhibited a coincidence of CTS and TF [21].

\section{DSA}

Kuntz et al. [22] first reported destructive spondyloarthropathy (DSA) as a new syndrome in dialysis patients in 1984. They described the specific features as microbial spondylitis, degenerative disc disease, and destructive spondyloarthropathy of calcium pyrophosphate dihydrate deposition disease. They insisted radiologic signs were essential for the diagnosis of DSA. The following findings served as base findings: severe narrowing of the intervertebral disc, erosions, and geodes of the adjacent vertebral plates, and absence of significant osteophytosis. The main lesions of DSA were highly mobile spine areas, such as C5-7 and L3-5 [23], and DSA was reported in approximately $20 \%$ of long-term dialysis patients [24, 25]. Chin et al. [26] divided the progression of DSA into four grades based on the radiological findings of the spines. Based on these results, the radiological examination can lead to a diagnosis of DSA and determine the progression.

DSA is exclusively confirmed in dialysis patients, but many types of spinal diseases exhibit clinical and radiological similarities. Spinal osteoarthritis (degenerative arthritis of the spine), infectious spondylitis, and psoriatic arthritis should be distinguished from DSA. The differentiation between spinal osteoarthritis and DSA is the most important among these conditions because the prevalence of spinal osteoarthritis is high in elderly patients. DSA exhibits a relatively low signal intensity on both T1- and T2-weighted images [27, 28]. DSA does not exhibit major osteophytosis in the lesion, whereas spinal osteoarthritis is frequently associated with apparent osteophytosis [26] (Fig. 3). These radiological points are important in the differentiation between spinal osteoarthritis and DSA.

\section{SCS}

Spinal canal stenosis (SCS) develops from spinal cord compression due to the narrowing of the canal space. Thickening of ligamentum flavum, protruded intervertebral discs, and bone spurs lead to a narrow canal. Rheumatoid arthritis, trauma, and compression fracture of vertebral bones occasionally induce SCS.

NASS guidelines [29] describe the definition of clinical SCS as follows: patients with history and physical examination findings consistent with a degenerative spinal cord. MRI is suggested as the most appropriate, non-invasive test to confirm the presence of anatomic narrowing of the spinal canal or the presence of nerve root impingement.

DSA and SCS associated with DRA exhibit a delayed appearance after CTS and TF in long-term hemodialysis patients [21] (Table 1). In our analysis, dialysis vintage values of patients with DSA and/or SCS versus that of patients without DSA and/or SCS were $362.5 \pm 133.4$ months and $298.0 \pm 127.8$ months $(p=0.039)$, respectively [21]. Among 30 cases with DSA and/or SCS, 23 cases $(76.7 \%)$ had CTS and/or TF.

\section{Bone cyst}

Bone cysts are typically divided into three groups: unicameral bone cyst, aneurysmal bone cyst, and traumatic bone cyst. Unicameral bone cyst or simple bone cyst is a benign, fluid-containing lesion. A simple cyst is frequently observed on the metaphysis of long bones, such as the proximal humerus or femur in children and adolescents [30]. The etiology is unknown, but occasionally unicameral bone cysts spontaneously disappear. An aneurysmal bone cyst is an expansive hemorrhagic lesion 

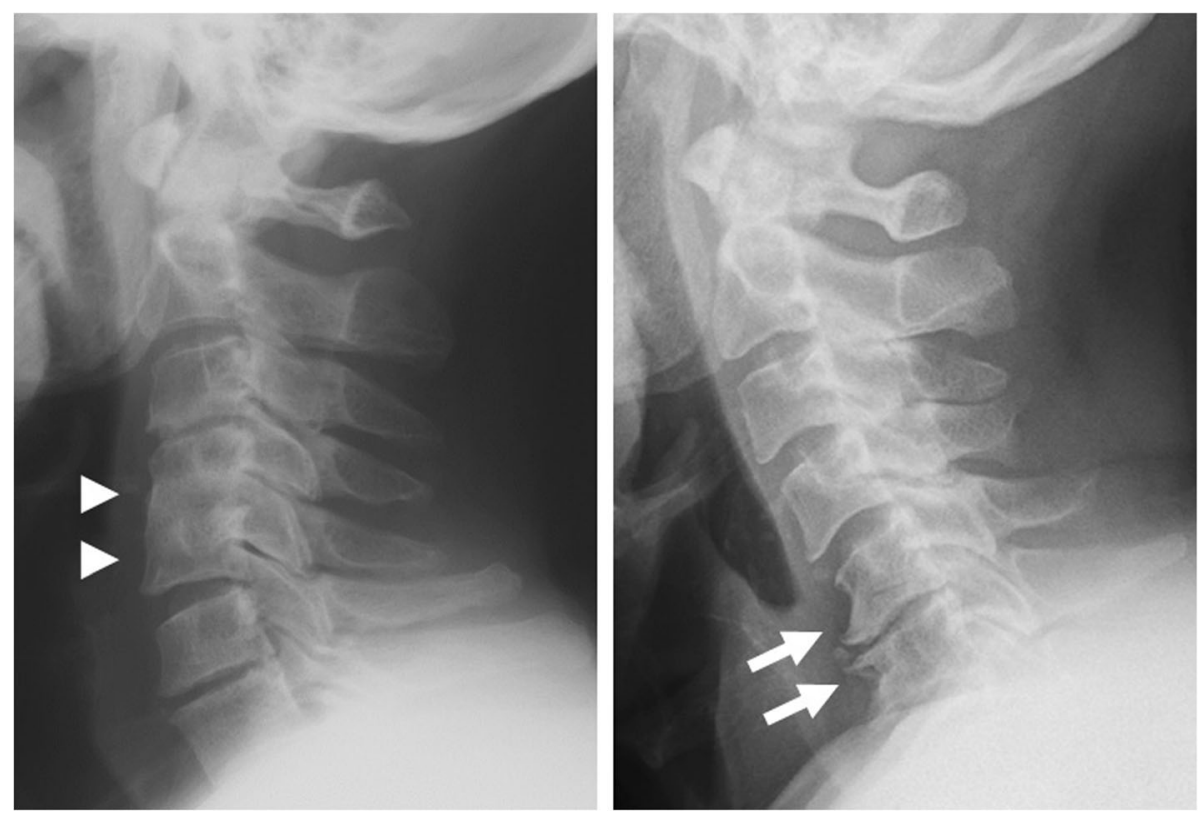

Fig. 3 Destructive spondyloarthropathy (DSA) and spondylosis on cervical spines. Left. DSA on cervical spine. Vertebral bodies from C4 to C6 show degenerative changes and fusion without osteophytosis (arrow heads). Right. Spondylosis on cervical spine. Vertebral bodies from C4 to C6 show degenerative changes with osteophytosis (arrows) and narrowing disc space without fusion between C5 and C6

and exhibits walled multicystic lesions [31]. Seventy-five to $90 \%$ of cases of traumatic bone cyst develop before the age of 20. A traumatic bone cyst is a rare non-epithelial-lined cyst found in the mandibular bone. The true etiology is unclear, but the lesion is called a traumatic cyst [32].

Almost all bone cysts found in long-term or older hemodialysis patients are associated with beta 2-microglobulin amyloid deposition. Only a portion of cysts is due to hyperparathyroidism. Proliferative synovial tissues invade into bone tissues and form bone cysts via amyloid deposition [33]. Sargent et al. [34] reported that the prevalence of bone cysts was 36\% in long-term dialysis patients $(n=58)$. Frequently affected sites included the phalanges, metacarpals, carpals, distal radius and ulna, proximal humerus, femoral head or neck, and acetabula. Fitzpatrick et al. [35] reported that multicystic tendency was a feature of bone cysts associated with DRA (Fig. 4). The incidence ages differ between non-dialysis bone cysts and dialysis bone cysts (Table 1).

\section{Multiple joints pain}

Bardin et al. [36] reported that multiple joints pain derived from DRA dramatically disappeared after kidney transplantation. After kidney transplantation, the number of painful joint sites was significantly reduced from 15 to 72 . Among multiple sites of joint pain, shoulder pain was most common. Hoshino et al. [37] compared the rates of multiple joints pain between DRA and non-DRA patients. The rate was $63.6 \%$ in DRA patients, whereas that in non-DRA patients was only $2.1 \%$. Multiple joints pain is considered a specific feature of DRA.

MRI and ultrasound sonography indicated the thickening of intra-articular tendons and the increase in bursal fluid in painful shoulder joints of dialysis patients [3840]. Amyloid deposition in synovial tissues may induce intra-articular inflammation related to joint pain.

\section{Other lesions of DRA}

Pathological bone fractures have been documented as a clinical finding of DRA [41, 42]. Major target lesions

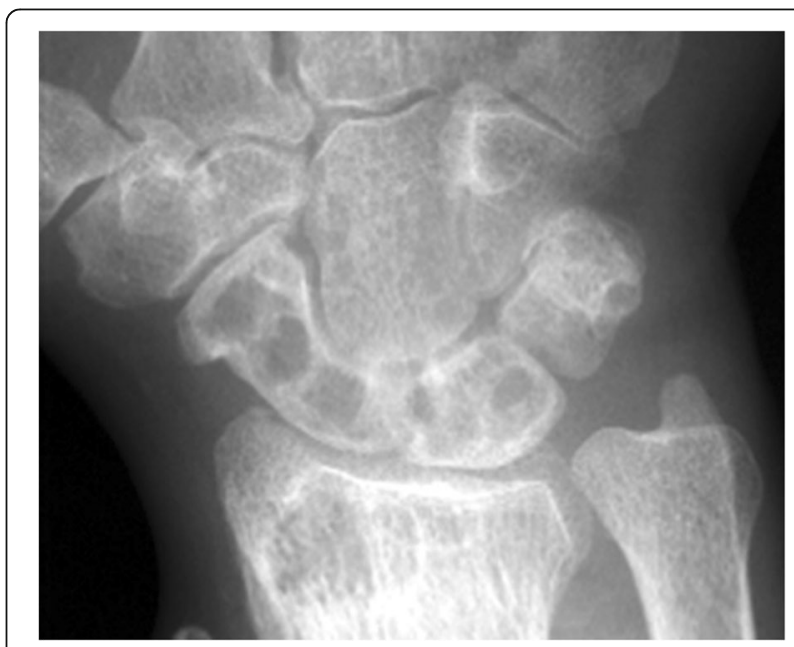

Fig. 4 Bone cysts on carpal bones and epiphyses on radial bone. Multiple bone cysts are observed 
included hip joints and femoral necks. Bone cyst formation and inflammation around the joints were suspected as the cause of pathological bone fracture due to DRA $[43,44]$. Walking disturbances are frequently noted in patients with DRA because they suffered from knee and shoulder joint pain [21]. The walking disturbance derived from joint pain occasionally causes falls, and traumatic bone fractures may easily appear in dialysis patients.

Ischemic colitis has been reported as a complication of long-term dialysis patients. To date, a few reports described that intestinal beta 2-microglobulin amyloid deposition developed into ischemic colitis [45, 46]. A part of ischemic colitis has been suspected an extra-articular lesion associated with DRA. The subcutaneous amyloid deposition has also been reported as an extra-articular lesion associated with DRA [47-49]. Preferred deposition sites include the gluteal and back regions. Subcutaneous amyloid depositions occasionally grow to a large-sized mass; therefore, it is called an amyloid ball. It has been rarely documented that beta 2-microglobulin amyloidosis was involved in the formation of renal stones in dialysis patients. Lysine-specific cleavage of beta 2-microglobulin was extracted from amyloid stones in dialysis patients [50-52].

Bone fracture, ischemic colitis, subcutaneous tumor, and renal stone in dialysis patients are potential lesions associated with DRA.

\section{The necessity of criteria for a clinical diagnosis of DRA}

We have discussed the difference in bone articular lesions between patients with or without DRA. DSA is a specific lesion of DRA, and other bone articular lesions have distinctive characteristics between the two groups with and without DRA (Table 2). Of course, we cannot perfectly differentiate both groups without pathological evidence. Chikawa et al. [53] compared the rates of amyloid deposition in operative specimens obtained from the decompression surgery of the spinal canal in DSA and SCS cases. The amyloid deposition rate was $100 \%$ in the DSA group, whereas the rate was decreased to $66.7 \%$ in SCS cases without DSA. Based on these facts, we believe that the criteria for the clinical diagnosis of DRA must be established based on a combination method for multiple DRA lesions.

\section{Validation of criteria for the clinical diagnosis of DRA}

Validation with pathological examination should be performed to ensure the adequacy of the criteria. As previously mentioned above, unfortunately, bone articular lesion biopsy is invasive and harmful. A few reports described the pathological diagnostic rate based on the surgical specimens. Chary-Valckenaere [54] and Kessler [55] reported that $68.3 \%$ and $62.0 \%$ of dialysis cases exhibited amyloid deposits in the surgical specimens from CTS. Jadoul et al. [56] studied the pathological rate of amyloid detection from postmortem evaluation concerning joint lesions. The amyloid deposition rates were $97 \%$ in sternoclavicular joints, $91 \%$ in knee joints, and $57 \%$ in shoulder joints. Based on these results, the clinical diagnosis exclusively based on one bone articular lesion seems less precise; however, clinical diagnosis based on two or more bone articular lesions promises increased accuracy.

The availability of criteria for the clinical diagnosis of DRA In the clinical setting, missing a DRA diagnosis represents a risk for dialysis patients. Severe cervical DSA may lead to spinal damage upon intratracheal intubation. Large bone cysts may cause bone fractures if falls occur. Proposed criteria are useful for the safety control of dialysis patients.

Hoshino et al. [37] evaluated the severity of dialysis-related amyloidosis based on DRA findings. They determined that DRA cases should exhibit at least two findings from the following five DRA-related findings: polyarthralgia, CTS, TF, DRA, or bone cysts. Based on the scoring system presented in Table 3 , they divided the amyloid scores into 3 categories, mild (A-score 3-4), moderate (5-7), and severe (8-10), based on SF-36v2 physical functioning score. The corresponding area under the receiver-operating characteristics curve for diagnosis of DRA was 0.9345 using a cut-off value of 4 . This result suggests that the clinical diagnostic criteria for DRA are also available for severity scoring of DRA.

\section{The treatments for DRA}

Unfortunately, we have no curative medicine for DRA. Prevention and early detection are important for DRA treatments. The accumulation of beta 2-microglobulin and inflammatory reaction in dialysis patients accelerate the amyloid deposition [57], therefore highly biocompatible and high-flux membranes have been recommended for a decrease in the incidence of DRA [58]. The use of ultrapure dialysate is also necessary as a preventive intervention [59]. Compared to conventional hemodialysis, hemodiafiltration and hemofiltration with higher removal efficacy of beta 2-microglobulin can effectively inhibit the progression of DRA [59]. In Japan,

Table 3 Dialysis-related amyloidosis clinical scoring system

\begin{tabular}{ll}
\hline Component score & 3 \\
\hline Polyarthralgia & 2 \\
Trigger finger & 2 \\
Carpal tunnel syndrome & 3 \\
Dialysis-related spondyloarthropathy & \\
\hline Total 10 &
\end{tabular}


beta 2-microglobulin absorption column has been approved by the insurance system. This absorption treatment is effective in particular for the joint pain relief derived from DRA and leads to the improvement of activity of daily life and sleeplessness [60]. Early kidney transplantation can prevent the incidence of DRA or ameliorate symptoms and sings associated with DRA, while it cannot perfectly cure the once developed DRA [61]. We would like everyone to use our clinical criteria for the early detection and the early start of prevention.

\section{Conclusions}

We compared the characteristics of bone articular lesions between the two groups: patients with and without DRA. Significant differences were confirmed between them. Thus, bone articular lesions in dialysis patients may suggest lesions associated with DRA. Unfortunately, biopsies of bone articular lesions are not easy; thus, we introduced criteria for the clinical diagnosis of DRA.

\section{Abbreviations \\ BC: Bone cyst; CTS: Carpal tunnel syndrome; DRA: Dialysis-related amyloidosis; DSA: Destructive spondyloarthropathy; SCS: Spinal canal stenosis; TF: Trigger finger}

\section{Acknowledgements}

This work was supported in part by a Grant-in-Aid from the Ministry of Health, Labour and Welfare of Japan. We are grateful for clinical data provided from the dialysis hospital by Kentaro Oomori, Isei Ei, Yutaka Oosawa, Yoshifumi Ubara, and Shigeko Hara.

\section{Funding}

Not applicable.

\section{Availability of data and materials}

The datasets used and analyzed during the current study are available from the corresponding author on reasonable request.

\section{Authors' contributions}

$\mathrm{SN}, \mathrm{SY}, \mathrm{JH}, \mathrm{KT}$, and $\mathrm{HN}$ contributed to the construction of clinical diagnostic criteria for DRA. SN was a major contributor in writing the manuscript. All authors read and approved the final manuscript.

\section{Authors' information}

The authors are members of Amyloidosis Research Group supported by the Ministry of Health, Labour and Welfare of Japan.

\section{Ethics approval and consent to participate}

Not applicable.

\section{Consent for publication}

Not applicable.

\section{Competing interests}

The authors declare that they have no competing interests.

\section{Publisher's Note}

Springer Nature remains neutral with regard to jurisdictional claims in published maps and institutional affiliations.

\section{Author details}

'Division of Nephrology and Kidney Center, Graduate School of Medicine, Kobe University, 7-5-2 Kusunoki-cho, Chuou-ku Kobe City, Hyogo Prefecture 650-0017, Japan. ²Division of Clinical Nephrology and Rheumatology, Graduate School of Medical and Dental Sciences, Niigata University, 1-757
Asahimachi-dori, Chuou-ku, Niigata City, Niigata Prefecture 951-8510, Japan. ${ }^{3}$ Nephrology Center, Toranomon Hospital, Toranomon, Minato-ku, Tokyo 105-8470, Japan. ${ }^{4}$ Department of Molecular Pathology, Faculty of Medical Sciences, University of Fukui, Fukui 910-1193, Japan.

Received: 19 October 2018 Accepted: 22 February 2019

Published online: 15 March 2019

\section{References}

1. Fenves AZ, Emmett M, White MG, Greenway G, Michaels DB. Carpal tunnel syndrome with cystic bone lesions secondary to amyloidosis in chronic hemodialysis patients. Am J Kidney Dis. 1986;7:130-4.

2. Gejyo F, Homma N, Arakawa M. Carpal tunnel syndrome and beta 2microglobulin-related amyloidosis in chronic hemodialysis patients. Blood Purif. 1988:6:125-31.

3. Otsubo S, Kimata N, Okutsu I, Oshikawa K, Ueda S, Sugimoto H, et al. Characteristics of dialysis-related amyloidosis in patients on haemodialysis therapy for more than 30 years. Nephrol Dial Transplant. 2009;24:1593-8.

4. Deramond H, Sebert $\mathrm{J}$, Rosat P, Fardellone P, Romero CA, Berlemont F. Destructive spondyloarthropathy in chronic haemodialysis patients. Current data and radiological aspects. J Neuroradiol. 1987;14:27-38.

5. Varga J, Fenves A. Destructive noninfectious spondyloarthropathy in hemodialysis patients. Radiology. 1987;164:584-5.

6. Ito M, Abumi K, Takeda N, Satoh S, Hasegawa K, Kaneda K. Pathologic features of spinal disorders in patients treated with long-term hemodialysis. Spine (Phila Pa 1976). 1998:23:2127-33.

7. Hardouin P, Flipo RM, Foissac-Gegoux P, Dumont A, Duquesnoy B, Delcambre B. Dialysis-related beta 2 microglobulin-amyloid arthropathy. Improvement of clinical symptoms after a switch of dialysis membranes Clin Rheumatol. 1988;7:41-5.

8. Takenaka R, Fukatsu A, Matsuo S, Ishikawa K, Toriyama T, Kawahara H. Surgical treatment of hemodialysis-related shoulder arthropathy. Clin Nephrol. 1992:38:224-30.

9. Nishi S. Clinical criteria of dialysis related amyloidosis and its evaluation. The reports for Amyloidosis Research Group study supported by a Grant-in-Aid from the Ministry of Health, Labour and Welfare of Japan, 2009; 13-15, Published in 2010 (in Japanese).

10. Hoshino J, Yamagata K, Nishi S, Nakai S, Masakane I, et al. Carpal tunnel surgery as proxy for dialysis-related amyloidosis: results from the Japanese society for dialysis therapy. Am J Nephrol. 2014;39:449-58.

11. McCarthy JT, Williams AW, Johnson WJ. Serum beta 2-microglobulin concentration in dialysis patients: importance of intrinsic renal function. J Lab Clin Med. 1994;123:495-505.

12. No authors. Practice parameter for carpal tunnel syndrome (summary statement). Report of the quality standards subcommittee of the American Academy of Neurology. Neurology. 1993:43:2406-2409.

13. El Miedany Y, Ashour S, Youssef S, Mehanna A, Meky FA. Clinical diagnosis of carpal tunnel syndrome: old tests-new concepts. Joint Bone Spine. 2008; 75:451-7.

14. Kolovos S, Tsiotas D. Ultrasonographic diagnosis of carpal tunnel syndrome: introducing a new approach. Eur J Orthop Surg Traumatol. 2016;26:167-75.

15. Guan W, Lao J, Gu Y, Zhao X, Rui J, Gao K. Case-control study on individual risk factors of carpal tunnel syndrome. Exp Ther Med. 2018;15:2761-6.

16. Hoshino J, Yamagata K, Nishi S, Nakai S, Masakane I, Iseki K, et al. Significance of the decreased risk of dialysis-related amyloidosis now proven by results from Japanese nationwide surveys in 1998 and 2010. Nephrol Dial Transplant. 2016:31:595-602

17. M'Bappe P, Grateau G. Osteo-articular manifestations of amyloidosis. Best Pract Res Clin Rheumatol. 2012:26:459-75.

18. Newport ML, Lane LB, Stuchin SA. Treatment of trigger finger by steroid injection. J Hand Surg Am. 1990;15:748-50.

19. McKee D, Lalonde J, Lalonde D. How many trigger fingers resolve spontaneously without any treatment? Plast Surg (Oakv). 2018;26:52-4.

20. Lin FY, Wu Cl, Cheng HT. Coincidence or complication? A systematic review of trigger digit after carpal tunnel release. J Plast Surg Hand Surg. 2018;52:67-73.

21. Nishi S, Hoshino J, Yamamoto S, Goto S, Fujii H, Ubara Y, et al. Multicentre cross-sectional study for bone-articular lesions associated with dialysis related amyloidosis in Japan. Nephrology (Carlton). 2018;23:640-5.

22. Kuntz D, Naveau B, Bardin T, Drueke T, Treves R, Dryll A. Destructive spondylarthropathy in hemodialyzed patients. A new syndrome. Arthritis Rheum. 1984;27:369-75. 
23. Maruyama H, Gejyo F, Arakawa M. Clinical studies of destructive spondyloarthropathy in long-term hemodialysis patients. Nephron. 1992;61: 37-44.

24. Fiocchi O, Bedani PL, Orzincolo C, Storari A, Cavazzini PL, Malacarne F, et al. Radiological features of dialysis amyloid spondyloarthropathy. Int J Artif Organs. 1989;12:216-22.

25. Leone A, Sundaram M, Cerase A, Magnavita N, Tazza L, Marano P. Destructive spondyloarthropathy of the cervical spine in long-term hemodialyzed patients: a five-year clinical radiological prospective study. Skelet Radiol. 2001;30:431-41.

26. Chin M, Hase H, Miyamoto T, Tsuji Y, Mikami Y, Kubo T. Radiological grading of cervical destructive spondyloarthropathy in long-term hemodialysis patients. J Spinal Disord Tech. 2006:19:430-5.

27. Theodorou DJ, Theodorou SJ, Resnick D. Imaging in dialysis spondyloarthropathy. Semin Dial. 2002;15:290-6.

28. Niu CC, Chen WJ, Chen LH, Shih CH. Destructive spondyloarthropathy mimicking spondylitis in long-term hemodialysis patients. Arch Orthop Trauma Surg. 2000;120:594-7.

29. NASS Clinical Guidelines. Diagnosis and Treatment of Degenerative Lumbar Spinal Stenosis. https://www.spine.org/Portals/0/Documents/ ResearchClinicalCare/Guidelines/LumbarStenosis.pdf. Revised in 2011.

30. Mascard E, Gomez-Brouchet A, Lambot K. Bone cysts: unicameral and aneurysmal bone cyst. Orthop Traumatol Surg Res. 2015;101:S119-27.

31. Kumar LKS, Kurien N, Thaha KA. Traumatic bone cyst of mandible. J Maxillofac Oral Surg. 2015;14:466-9.

32. Satish K, Padmashree S, Rema J. Traumatic bone cyst of idiopathic origin? A report of two cases. Ethiop J Health Sci. 2014;24:183-7.

33. Gielen JL, van Holsbeeck MT, Hauglustaine D, Verresen L, Verbeken E, Baert AL, et al. Growing bone cysts in long-term hemodialysis. Skelet Radiol. 1990;19:43-9.

34. Sargent MA, Fleming SJ, Chattopadhyay C, Ackrill P, Sambrook P. Bone cysts and haemodialysis-related amyloidosis. Clin Radiol. 1989;40:277-81.

35. Fitzpatrick DC, Jebson PJ, Madey SM, Steyers CM. Upper extremity musculoskeletal manifestations of dialysis-associated amyloidosis. lowa Orthop J. 1996:16:135-8.

36. Bardin T, Lebail-Darne JL, Zingraff J, Laredo JD, Voisin MC, Kreis H, et al. Dialysis arthropathy: outcome after renal transplantation. Am J Med. 1995; 99:243-8.

37. Hoshino J, Kawada M, Imafuku A, Mise K, Sumida K, Hiramatsu R, et al. A clinical staging score to measure the severity of dialysis-related amyloidosis. Clin Exp Nephrol. 2017:21:300-6.

38. Escobedo EM, Hunter JC, Zink-Brody GC, Andress DL. Magnetic resonance imaging of dialysis-related amyloidosis of the shoulder and hip. Skelet Radiol. 1996:25:41-8

39. Turk AC, Fidan N, Ozcan O, Ozdemir F, Tomak L, Ozkurt S, et al. Painful and painless shoulder magnetic resonance imaging comparisons in hemodialysis patients and correlation with clinical findings. J Back Musculoskelet Rehabil. 2016. https://doi.org/10.3233/BMR-160715.

40. Kay J, Benson CB, Lester S, Corson JM, Pinkus GS, Lazarus JM, et al. Utility of high-resolution ultrasound for the diagnosis of dialysis-related amyloidosis. Arthritis Rheum. 1992;35:926-32.

41. Campistol JM, Sole M, Munoz-Gomez J, Riba J, Ramon R, Revert L. Pathological fractures in patients who have amyloidosis associated with dialysis. A report of five cases. J Bone Joint Surg Am. 1990;72:568-74.

42. Kazama JJ, Yamamoto S, Wakasugi M. Narita I. A hip fracture in a dialysis patient with Abeta2M amyloidosis. Kidney Int. 2014:85:214-5.

43. Naito M, Ogata K, Shiota E, Oyama M. Amyloid bone cysts of the femoral neck. Impending fractures treated by curettage and bone grafting. J Bone Joint Surg Br. 1994;76:922-5.

44. Kazama JJ, Maruyama H, Gejyo F. Osteoclastogenesis and osteoclast activation in dialysis-related amyloid osteopathy. Am J Kidney Dis. 2001;38:S156-60.

45. Biggers JA, Remmers AR Jr, Lindley JD, Folse DS, Sarles HE, Fish JC. Femoral neuropathy and ischemic colitis associated with amyloidosis in hemodialysis patients. Ann Surg. 1975;182:161-2.

46. Saito A, Gejyo F. Current clinical aspects of dialysis-related amyloidosis in chronic dialysis patients. Ther Apher Dial. 2006;10:316-20.

47. Miyata T, Nakano T, Masuzawa M, Katsuoka K, Kamata K. Beta2microglobulin-induced cutaneous amyloidosis in a patient with long-term hemodialysis. J Dermatol. 2005;32:410-2.

48. Shimizu S, Yasui C, Yasukawa K, Nakamura H, Shimizu H, Tsuchiya K. Subcutaneous nodules on the buttocks as a manifestation of dialysis-related amyloidosis: a clinicopathological entity? Br J Dermatol. 2003;149:400-4.
49. Gargallo V, Angulo L, Hernandez E, Peralto JL, Zarco C. Massive subcutaneous masses on the back related to beta2-microglobulin amyloidosis. JAMA Dermatol. 2015;151:564-5.

50. Bommer J, Waldherr R, Ritz E. Kidney lesions in uraemic patients and beta 2microglobulin derived amyloid. Lancet. 1985;2:1437-8.

51. Ozasa H, Ota K. Mechanism of kidney stone formation in chronic hemodialysis patients. Nephron. 1991;58:242-3.

52. Linke RP, Hampl H, Lobeck H, Ritz E, Bommer J, Waldherr R, et al. Lysinespecific cleavage of beta 2-microglobulin in amyloid deposits associated with hemodialysis. Kidney Int. 1989;36:675-81.

53. Chikawa T, Sakai T, Bhatia NN, Miyagi R, Sairyo K, Goda Y, et al. Clinical outcomes of spinal surgery in patients treated with hemodialysis. J Spinal Disord Tech. 2013;26:321-4.

54. Chary-Valckenaere I, Kessler M, Mainard D, Schertz L, Chanliau J, Champigneulle J, et al. Amyloid and non-amyloid carpal tunnel syndrome in patients receiving chronic renal dialysis. J Rheumatol. 1998;25:1164-70.

55. Kessler M, Netter P, Azoulay E, Mayeux D, Pere P, Gaucher A. Dialysisassociated arthropathy: a multicentre survey of 171 patients receiving haemodialysis for over 10 years. The Co-operative Group on Dialysisassociated Arthropathy. Br J Rheumatol. 1992;31:157-62.

56. Jadoul M, Garbar C, Noel H, Sennesael J, Vanholder R, Bernaert P, et al. Histological prevalence of beta 2-microglobulin amyloidosis in hemodialysis: a prospective post-mortem study. Kidney Int. 1997;51:1928-32.

57. Kaneko S, Yamagata K. Hemodialysis-related amyloidosis: is it still relevant? Semin Dial. 2018;31:612-8

58. Schiffl H. Impact of advanced dialysis technology on the prevalence of dialysis-related amyloidosis in long-term maintenance dialysis patients. Hemodial Int. 2014:18:136-41.

59. Gejyo F, Amano I, Ando T, Ishida M, Obayashi S, et al. Society of $\beta 2$ microglobulin adsorption therapy. Survey of the effects of a column for adsorption of $\beta 2$-microglobulin in patients with dialysis-related amyloidosis in Japan. Ther Apher Dial. 2013;17:40-7.

60. Campistol JM. Dialysis-related amyloidosis after renal transplantation. Semin Dial. 2001;14:99-102

61. Scarpioni R, Ricardi M, Albertazzi V, De Amicis S, Rastelli F, et al. Dialysisrelated amyloidosis: challenges and solutions. Int J Nephrol Renovasc Dis. 2016;9:319-28.
Ready to submit your research? Choose BMC and benefit from:

- fast, convenient online submission

- thorough peer review by experienced researchers in your field

- rapid publication on acceptance

- support for research data, including large and complex data types

- gold Open Access which fosters wider collaboration and increased citations

- maximum visibility for your research: over $100 \mathrm{M}$ website views per year

At BMC, research is always in progress.

Learn more biomedcentral.com/submissions 